\title{
Quaternary-A Multidisciplinary Integrative Journal to Cope with a Complex World
}

\author{
Valentí Rull \\ Institute of Earth Sciences Jaume Almera (ICTJA-CSIC), Lluís Solé i Sabarís s/n, 08028 Barcelona, Spain; \\ vrull@ictja.csic.es
}

Published: 14 September 2017

We live in a Quaternary world, that is, a world shaped by the interplay of the different compartments of the earth system-lithosphere, hydrosphere, atmosphere, biosphere, cryosphere - during the last $~ 2.6$ million years. It is not possible to understand the current world—and, hence, to anticipate its possible future developments-without knowing the Quaternary history of drivers, processes, and mechanisms that have generated it. Our own species is an evolutionary outcome of the Quaternary performance. The aim of this editorial is to emphasize the special character of the Quaternary period with respect to former units of the geological time scale and the significance of differential traits in the shaping of modern earth. This is not a comprehensive account but a sample of selected relevant patterns and processes, aimed at illustrating the influence of Quaternary natural history on the present configuration of our planet. The objective is to introduce the new journal Quaternary, which is born with the aim of being an integrative journal to encompass all aspects of Quaternary science focused on understanding the complex world in which we live and to provide a sound scientific basis to anticipate possible future trends and inform environmental policies.

\section{The Quaternary World}

Climatic shifts, especially the alternation of glacial and interglacial phases, governed by astronomical cycles-i.e., the Milankovitch cycles-have been major drivers of Quaternary change. Continental drift and the associated palaeographic and palaeotopographic rearrangements, although present, have had comparatively lower influence than in former times, as the modern configuration of crustal plates was already set at the beginning of the Quaternary. Paleographic and tectonic changes may have had local or regional influences, but the major global driver of Quaternary change was climatic variability. Glacial-interglacial cycles of 41,000 and 100,000-year period have been the more conspicuous climatic shifts but others acting at different spatial and temporal scales and controlled by either cyclic or non-cyclic drivers and mechanisms have also been influential.

A major mechanism for redistributing heat all over the earth is the oceanic thermohaline circulation, also known as the conveyor belt, generated and maintained by winds and regional disparities in water density due to temperature and salinity differences. Past changes in these circulation patterns are thought to have been responsible for the alternation of episodic or abrupt climatic shifts of one or few millennia duration called stadials (cold reversals) and interstadials (warm reversals). The position of the Intertropical Convergence Zone (ITCZ) - the near-Equatorial belt where trade winds converge, defining a high precipitation zone which latitudinal movement throughout the year is responsible for the intertropical precipitation seasonality-has experienced long-term shifts during the Quaternary that have also contributed to climatic variability at centennial to millennial scales.

Other climatic mechanisms acted at lower temporal scales. For example, the 11-year period solar sunspot cycle affects the intensity of solar radiation coming to the earth, which has been associated with recurrent decadal to centennial temperature and precipitation shifts during the Quaternary, especially in the Holocene. Interannual variations in the geographical position, intensity, and cyclicity of weather 
phenomena such as the Pacific El Niño-Southern Oscillation (ENSO) or the North Atlantic Oscillation (NAO), which control regional precipitation patterns, have also been influential in Quaternary climatic variability. Volcanic activity was also important during the Quaternary and has affected not only local landscape features but also regional and eventually global climates, owing to the cooling effect produced by the attenuation of the incoming solar radiation by volcanic dust and gases released to the atmosphere.

All of these climatic phenomena have been coupled across different spatial and temporal scales, defining a complex interplay of feedbacks and synergies resulting in Quaternary climatic variability. Quaternary climatic changes and their consequences have totally changed the face of the earth, thus leading to the new world in which we live.

Climate variability and changes in global biogeochemical cycles are intimately linked, as manifested in conspicuous changes in the chemical composition of the atmosphere and ocean waters. For example, the atmospheric concentration of greenhouse gases such as $\mathrm{CO}_{2}$ or $\mathrm{CH}_{4}$ has been significantly higher during warm and wet interglacials/interstadials than during cold and dry glacials/stadials. These changes have been related to shifts in the sources and sinks of these gases as a result of major biogeochemical reorganizations involving all the compartments of the earth system, notably the biosphere (vegetation cover, aquatic production), the lithosphere (rock weathering, volcanism), the hydrosphere (wetland extent, ocean absorption rates), and the atmosphere (oxidizing capacity). Therefore, the chemical composition of the atmosphere could be considered a diagnostic proxy for the biogeochemichal state of the earth system, in a similar sense that the chemical composition of blood is used to assess human health.

Every landscape and environment of the planet, from the deep sea to the highest mountains, has been modeled by or has the imprint of processes which occurred during the Quaternary. For example, the flat ocean floor is mostly Quaternary as the first tens to hundreds of meters of sediments were deposited during this period. Coastal terrains have been deeply affected worldwide by eustatic sea-level oscillations linked to glacial-interglacial cycles. For example, during the last glaciation, sea levels were $\sim 120 \mathrm{~m}$ below present ones (lowstand), continental shelves were exposed and coastal erosion was favored, whereas during present-day interglacial conditions, high sea levels (highstand) have inundated the continental shelf again favoring accretion and delta expansion. High-mountain landscapes have been largely modelled by glacial erosion and the resulting sedimentary byproducts. Concerning lakes, a large number of them, notably those situated at high elevations and high latitudes are of glacial origin and their sediments started to accumulate after the last glaciation. Other lakes are older due to tectonic subsidence and their sedimentary infill may encompass the whole Quaternary. Polar ice caps also contain a significant Quaternary component that may be kilometers thick.

At higher latitudes, the recurrent glacial-interglacial freeze and thaw of large and thick ice masses has been a significant landscape modeler due to the alternative subsidence (glacial depression) and emergence (interglacial rebound) of glaciated lands. The northernmost parts of Eurasia and America have been intermittently eroded to the rock basement by ice sheets, hence, landscape development has been entirely reset after each glaciation. Non-glaciated areas of North America and central Europe, which were under permafrost conditions during the last glaciation, experienced significant shifts in drainage and erosion/sedimentation patterns during interglacials, leading to the formation of present river networks and fluvial terraces, as well as the development of totally new edaphic and vegetation patterns. The modern distribution of ecosystems and human societies, their cities, communication networks, land-use patterns, etc. are a consequence of interglacial Holocene processes that have modified the glacial and periglacial terrains of the last glaciation.

At lower latitudes, the effects of Quaternary climate changes have been differently but equally influential. For example, spatial rearrangements in precipitation patterns have led to the recurrent expansion and contraction of major deserts, as well as the alternation of deserts and humid environments with permanent lakes in certain non-glaciated areas. With some exceptions, deserts seem to have generally expanded during glacial phases. There is a controversy as to whether or not 
glacial climates have been generally arid by a general decrease of water availability due to general ice growth. Other characteristic Quaternary features are the accumulation of fine wind-blown silt (loess) coming from deserts or periglacial areas in large areas of Asia, Europe, North America, and southern South America, among others.

The tropics were also affected by glacial-interglacial cycles. Indeed, topical mountains were glaciated on their higher elevations, which produced the same landscape and environmental modifications as in temperate mountains. Even tropical lowlands were affected by Quaternary climatic variability. The debate on extensive aridity during the last glaciation is especially active for the lowland tropics, where extensive areas currently covered by rainforests-for example, the Amazonia or central Africa-could have been occupied by deserts and dry savannas during the Last Glacial Maximum (LGM), as a model for a typical glaciation. All these phenomena, and others also linked to climatic shifts, determined landscape rearrangements similar to those mentioned for high-latitude glacial and periglacial zones of the last glaciation, leading to profound environmental transformations.

For living beings, the Quaternary has been a time of biological evolution and ecological revolution. The old idea that most living species were already present at the beginning of the Quaternary and that the environmental shifts of this period have favored extinction and biodiversity depletion is challenged by new discoveries. This could be true locally, especially in some temperate areas under the influence of recurrent glaciation and periglacial climates. However, biological evolution has been very active and many species emerged during the Quaternary under the influence of climatic change and its consequences. In some areas, as for example the tropics or the Mediterranean region, the Quaternary was a time of net diversification-i.e., the relationship between speciation and extinction-among many taxonomic groups, responsible not only for the formation of many new species but also for the enhancement of genetic diversity of the already existing ones. From a biological perspective, the Quaternary can be viewed as the interface between ecology and evolution, as it enables the study of microevolutionary patterns and processes at a (meta)population level in an ecological context, which is essential to assessing and understanding the environmental and ecological drivers and mechanisms involved in speciation processes. In this way, the Quaternary time frame could be considered the missing link between evolutionary deep-time and the present.

The main ecological revolution occurred is the shaping of modern biomes and ecosystems, especially in the formation of present-day living communities and the potential influence of internal ecological factors and external environmental drivers in this process. Community assembly is a highly debated topic in modern ecology that can benefit from the knowledge of past trends in ecosystem dynamics, especially during the Quaternary. At the community level, the main consequence of Quaternary climatic changes has been a significant turnover in taxonomic structure and species' relative abundance leading to a constantly changing community composition, owing to the different sensitivity of individual species to climatic forcing. Present-day ecosystems are entirely a Quaternary innovation as they did not exist in former times. Therefore, Quaternary palaeoecology is needed for ecological study, especially for the understanding of long-term processes imperceptible at human time scales. One of the main lessons that the Quaternary study has provided in this sense is that past, present, and future are human constructions and that time is a continuum through which species and communities flow, interact, and evolve. A biosphere of the past and a biosphere of the present do not exist separately; there is a single biosphere where ecological and evolutionary processes have occurred continuously since the origin of life on earth. Therefore, there is no ecology of the past and no ecology of the present, but rather a single ecology that includes both.

From a biogeographical point of view, the main effect of Quaternary climatic changes has been a spatial rearrangement of biotas, due to range shifts and migratory movements as a response to changing environmental conditions. For example, during the last glaciation, species of present-day European and North American forests were refugiated into small areas of the southern part of these continents. The incoming of interglacial conditions favored the progressive recolonization of these continents from the southern refugia leading to present-day situation. Eustatic sea-level oscillations 
deeply affected island biotas. Lowstand glacial conditions favored physical interconnection of oceanic islands among them and also of continental islands with the mainland, whereas interglacial highstands isolated islands' biotas. The situation was similar for high-mountain biotas, for which interglacial warmings favored isolation on mountaintops and glacial coolings promoted connection by downward migration. Recurrent isolation (which favored vicariance) and connection (which promoted gene flow) of refugial areas, islands, and high-mountain biomes have had important biogeographical and evolutionary consequences, especially for speciation processes and the development of current endemism patterns.

A unique feature of the Quaternary, as compared to other periods, is the presence of hominins of the genus Homo, who also have contributed to the shaping of modern landscapes. Noteworthy, our own species (Homo sapiens) has profoundly altered the physical and biological world, the biogeochemical patterns and processes of the biosphere, and also global climates. Human activities and their consequences are additional drivers of ecological and environmental change exclusive to the Quaternary and a fundamental ingredient to be considered in palaeoenvironmental reconstruction. This has been true for the last millennia-especially since the so called Neolithic revolution, when agriculture appeared and landscape transformation experienced a significant acceleration-but especially significant in the last centuries, when we have turned into an additional telluric force that has influenced not only the functioning of the earth system as a whole and its global biogeochemical cycles, but has also deeply transformed the surface of the earth and is actively contributing to biodiversity depletion and to the exhaustion of natural resources. This is why some have defined another 'sphere' in the earth system activity - the anthroposphere-characterized by humans and all the associated elements and processes. In recent decades, the informal term 'Anthropocene' has been widely used to refer to a new state of the earth system under the global influence of human activities. Some use this term simply as a new cultural phase of earth's history but others actively push for the 'Anthropocene' to become a new stratigraphic unit, a formal epoch of the geological time scale following the Holocene.

\section{The Quaternary Study}

With all these premises, Quaternary science emerges as a complex field faced to study the physical, chemical, biological, and anthropogenic processes-as well as their interactions, feedbacks, and synergies - which have shaped the earth and have delineated the system we observe today. Empirical evidence for the study of Quaternary patterns and processes lies on a varied range of sedimentary archives and involve a large amount and variety of biotic and abiotic indicators or proxies. In addition, knowledge generated by the study of the Quaternary has multiple applications, as many processes and phenomena can be considered past analogs for understanding present-day features and to anticipate potential future outcomes.

Quaternary archives are varied including sedimentary settings such as outcrops, lakes and other wetlands, oceans, fluvial basins, caves and other archaeological sites, etc. Non-sedimentary archives, as for example written historical documents, are also increasingly used in palaeoclimatic studies. Recently, a new type of non-sedimentary archive, the genes of living beings, has experienced a remarkable bourgeoning with the development of molecular analytical techniques. The genes contain information accumulated over millions of years, which can reveal the Quaternary evolutionary history of a given lineage. The amount and variety of physical, chemical, biological, and human proxies of Quaternary change is also noteworthy. In addition to the classical proxies, as for example, lithology, sedimentology, geochemistry, fossils, human tools, etc., a new type of indicators, the molecular proxies or biomarkers, has undergone significant growth in recent years. The diversity of archives and proxies has also contributed to the enhancement of approaches and disciplines participating in the study of the Quaternary. Multiproxy studies based on a range of diverse and independent proxies with the participation of researchers from different disciplines are the better suited to obtain holistic Quaternary reconstructions, avoiding circular reasoning. Quaternary science is, therefore, intrinsically multidisciplinary and needs contributions from all study areas of earth sciences and more. 
The generation of scientific knowledge makes sense by itself and does not need a pragmatic justification. However, Quaternary science goes farther as it has varied practical applications. For example, understanding the drivers, processes, and mechanisms involved in Quaternary climatic changes and their consequences for earth system configuration and dynamics is essential to address relevant issues such as optimized predictions of future climate change. Similarly, the study of phenomena such as volcanism, earthquakes, tsunamis, landslides, droughts, floods, etc. may help in improving risk assessment performance and prevention practices in the face of these natural hazards. The study of the responses of organisms and their communities to past climate changes may provide insights on their potential reactions to future environmental change, which can be useful for anticipating potential range shifts, extinctions, or community changes which can inform conservation and restoration practices. Disentangling the effects of natural and anthropogenic drivers of climatic and ecological shifts may be useful for the prediction of future ecological trends under changing climatic conditions and human practices, which may contribute to optimize resource management in the way towards more sustainable practices at local, regional, and global scales. A number of tools, methods, and proxies used in Quaternary studies also have applications in forensic science. Perhaps the better known is the study of pollen as an indicator of crime scenarios, but others including other biological proxies, as well as soil and sediment properties, are also worth mentioning.

\section{The Quaternary Journal}

This journal wants to emphasize the interdisciplinary nature of Quaternary science and, although there is no restriction on the type of papers to be published, it encourages the submission of manuscripts addressing the multidisciplinarity of Quaternary study and the complexity of the Quaternary world. To accommodate the widest range possible of scientific disciplines, the journal considers any type of study addressing any topic of Quaternary science (http:/ / www.mdpi.com/journal/quaternary / about). The following are examples sorted by broad disciplines but many others are possible:

- Geology and physical geography: stratigraphy, sequence stratigraphy, sea-level history, chronology and correlation, palaeontology, tectonics, geophysics, volcanology, petrology, mineralogy, geomorphology, sedimentology, soil science, palaeohydrology, limnogeology, glaciology, natural hazards.

- Paleoclimatology: palaeoclimatic reconstruction, explanatory and predictive modelling, ocean and atmosphere composition and dynamics, global biogeochemical cycles, episodic and abrupt climatic changes, feedbacks and linear responses, high-resolution palaeoclimatology, long records, dendroclimatology, historical documentary archives.

- Paleoecology: long-term ecological dynamics (terrestrial, marine, and freshwater ecosystems), biotic responses to environmental change, community assembly and succession, ecological impact of human activities, non-analogue and novel ecosystems, climate-human-ecosystem feedbacks and synergies.

- Biogeography and evolution: range shifts and environmental drivers, origin of latitudinal biodiversity gradients and macroecological patterns, speciation and extinction, diversification drivers, population dynamics and evolution, DNA phylogenetic and phylogeographic studies.

- Archaeology and anthropology: evolution of genus Homo, origin and evolution of Homo sapiens, Neanderthal extinction, palaeoanthropology, human palaeoecology, migrations and colonization, fire history, Neolithic revolution, ancient DNA studies, cultural evolution.

- 'Anthropocene' issues: humanization of earth system, global biogeochemical changes, anthropogenic climate change, chronostratigraphic and geochronological characterization, definition of GSSP and stratigraphic markers.

- Methodological issues: palaeoarchives and field methods, laboratory procedures, dating and age-depth modelling, data analysis and graphical display, global databases, high-resolution 
archives (tree rings, corals, laminated sediments, etc.), novel palaeoclimatic and palaeoecological proxies, GIS tools in palaeosciences.

- Applications: future climatic predictions, monitoring, prediction and risk assessment of natural hazards, palaeoecological significance for biodiversity conservation, landscape restoration and resource management, Quaternary proxies in forensic science.

Due to the great variety of possible targets and approaches in Quaternary science, this is not a comprehensive account of all the existing possibilities. We encourage potential contributors to submit manuscripts on Quaternary topics not included in this list or to contact the Editorial Office in case of doubt.

By default, the journal adopts the chronostratigraphic framework approved by the International Commission on Stratigraphy and the rules of the international stratigraphic guide, at the time of manuscript submission. However, proposals for the modification of the current stratigraphic framework are also welcome, provided they are based on scientific criteria. At present, the Quaternary is the geological period starting 2.588 million years ago, defined by the base of the Gelasian stage and characterized by the development of widespread glaciations in mid-northern latitudes. The Quaternary has been subdivided into two epochs: the Pleistocene, the glacial epoch par excellence; and the Holocene, whose onset has been placed 11,700 years before present, coinciding with the first signs of warming leading to present-day climates. Under the current stratigraphic rules, the 'Anthropocene' is an informal term to designate a prospect for a proposal of a new epoch of the geological time scale. However, empirically-based papers defending different 'Anthropocene' conceptions are welcome, especially proposals for global GSSP and suitable stratigraphic markers.

Quaternary accepts papers of different types (research articles, reviews, comments, technical notes) and is also interested in essays, which we call 'palaeoinsights', to address philosophical issues, controversial topics, new and original perspectives and unconventional approaches to existing problems or insights on science and society and the future of palaeosciences. It is important to emphasize that there is no restriction on paper length, so potential contributors are encouraged to include all details that they consider adequate to raise their points. However, papers should be consistent structurally and thematically. More details are provided in the journal's instructions for authors (http:/ / www.mdpi.com/journal/quaternary/instructions). The journal welcomes proposals for thematic special issues. These proposals are evaluated by the Editor-in-Chief and the Associate Editors, who decide on the suitability and feasibility of the special issue.

Quaternary aims to be a high-quality and influential journal, for which we have assembled a high-quality team of Associate Editors and Editorial Board members (i.e., the Academic Editors) covering as many aspects of the Quaternary study as possible, and have strict rules for the acceptance of manuscripts for publication. All manuscripts submitted to the journal are peer-reviewed by at least two reviewers free from conflict of interest with authors. Scientific quality is the only criterion of acceptance of manuscripts for publication, editorial rejection based on the expected impact of papers is not contemplated. However, low-quality and/or poorly-written manuscripts will be rejected by the handling editors without progressing to peer review. Handling editors are usually the Associate Editors of the journal, who are responsible for the final decision on the acceptance or not of manuscripts to be published, after ratification of the Editor-in-Chief. However, members of the Editorial Board are also entitled of handling and making decisions on manuscripts when the topic fits better within their field of expertise. In the case of special issues, the handling editors are the Guest Editors, usually the special issue proponents, who should follow the journal's editorial rules, with the advice of the Academic Editors and the Editorial Office.

I would like to place special emphasis on publishing ethics, which are fundamental for our journal to assure high scientific quality and to prevent eventual bad practices. The authors' instructions are very clear and detailed about issues as for example, conflict of interest, double submission, plagiarism, data fabrication, image manipulation, fake authorship, and othersthat are obviously unacceptable in this and any other scientific publication. Other matters, such as qualification for authorship, are more 
heterogeneous across journals. Besides some general rules regarding the actual involvement of all authors in an article and their willingness to be listed as authors, we have some particularities that should be considered. A general rule is that the contribution of each author to the work (study concept and design, data analysis and interpretation, manuscript drafting, critical revision for substantial intellectual content, etc.) should be specified but our journal has some specific rules for authorship qualification. For example, funding acquisition, data collection, manuscript reading, or general supervision of the research group do not, by themselves, justify authorship. Scholars engaged in these tasks should appear in the acknowledgements. Potential contributors are encouraged to carefully read the sections 'Qualification for Authorship', 'Editorial Procedures and Peer Review', and 'Publication Ethics Statement' to be fully aware of the journal policies in ethical matters.

(C) 2018 by the author. Licensee MDPI, Basel, Switzerland. This article is an open access article distributed under the terms and conditions of the Creative Commons Attribution (CC BY) license (http:// creativecommons.org/licenses/by/4.0/). 